\title{
Wind Tunnel Test of Subscale Ringsail and Disk-Gap-Band Parachutes
}

\author{
Carlie H. Zumwalt, ${ }^{1}$ Juan R. Cruz ${ }^{2}$, Donald F. Keller ${ }^{3}$ \\ NASA Langley Research Center, Hampton, Virginia 23681 \\ Clara O'Farrell ${ }^{4}$ \\ Jet Propulsion Laboratory, California Institute of Technology, Pasadena, California 91109
}

\begin{abstract}
A subsonic wind tunnel test was conducted to determine the drag and static aerodynamic coefficients, as well as to capture the dynamic motions of a new Supersonic Ringsail parachute developed by the Low Density Supersonic Decelerator Project. To provide a comparison against current Mars parachute technology, the Mars Science Laboratory's Disk-Gap-Band parachute was also included in the test. To account for the effect of fabric permeability, two fabrics ("low" and "standard" permeability) were used to fabricate each parachute canopy type, creating four combinations of canopy type and fabric material. A wide range of test conditions were covered during the test, spanning Mach numbers from 0.09 to 0.5 , and static pressures from 103 to 2116 psf (nominal values). The fabric permeability is shown to have a first-order effect on the aerodynamic coefficients and dynamic motions of the parachutes. For example, for a given parachute type and test condition, models fabricated from "low" permeability fabric always have a larger drag coefficient than models fabricated from "standard" permeability material. This paper describes the test setup and conditions, how the results were analyzed, and presents and discusses a sample of the results. The data collected during this test is being used to create and improve parachute aerodynamic databases for use in flight dynamics simulations for missions to Mars.
\end{abstract}

\section{Nomenclature}

$\begin{array}{ll}C_{D} & =\text { drag coefficient } \\ C_{m} & =\text { pitching moment coefficient } \\ C_{m, \mathrm{SLCP}} & =\text { pitching moment coefficient about the suspension lines confluence point } \\ C_{m, \mathrm{TBCP}} & =\text { pitching moment coefficient about the triple bridle confluence point } \\ C_{N} & =\text { normal force coefficient } \\ C_{T} & =\text { tangential force coefficient } \\ C_{\mathrm{Tot}} & =\text { total force coefficient } \\ D_{F} & =\text { forebody maximum diameter } \\ D_{0} & =\text { nominal diameter } \\ \mathbf{F}_{\mathrm{Tot}} & =\text { total force vector } \\ F_{\mathrm{Tot}} & \text { magnitude of the total force vector } \\ F_{X, T D T}, F_{Y, T D T} & F_{Z, T D T} \quad \text { force components along the TDT coordinate system axes } \\ L_{\mathrm{Riser}} & =\text { riser length } \\ L_{\mathrm{Tot}} & =\text { total parachute length (apex to triple bridle confluence point) } \\ M & =\text { Mach number }\end{array}$

\footnotetext{
${ }^{1}$ Aerospace Engineer, Atmospheric Flight and Entry Systems Branch, AIAA Member.

${ }^{2}$ Aerospace Engineer, Atmospheric Flight and Entry Systems Branch, AIAA Member.

${ }^{3}$ Aerospace Research Engineer, Aeroelasticity Branch.

${ }^{4}$ Guidance and Control Engineer, EDL Guidance and Control Systems Group, AIAA Member.
} 


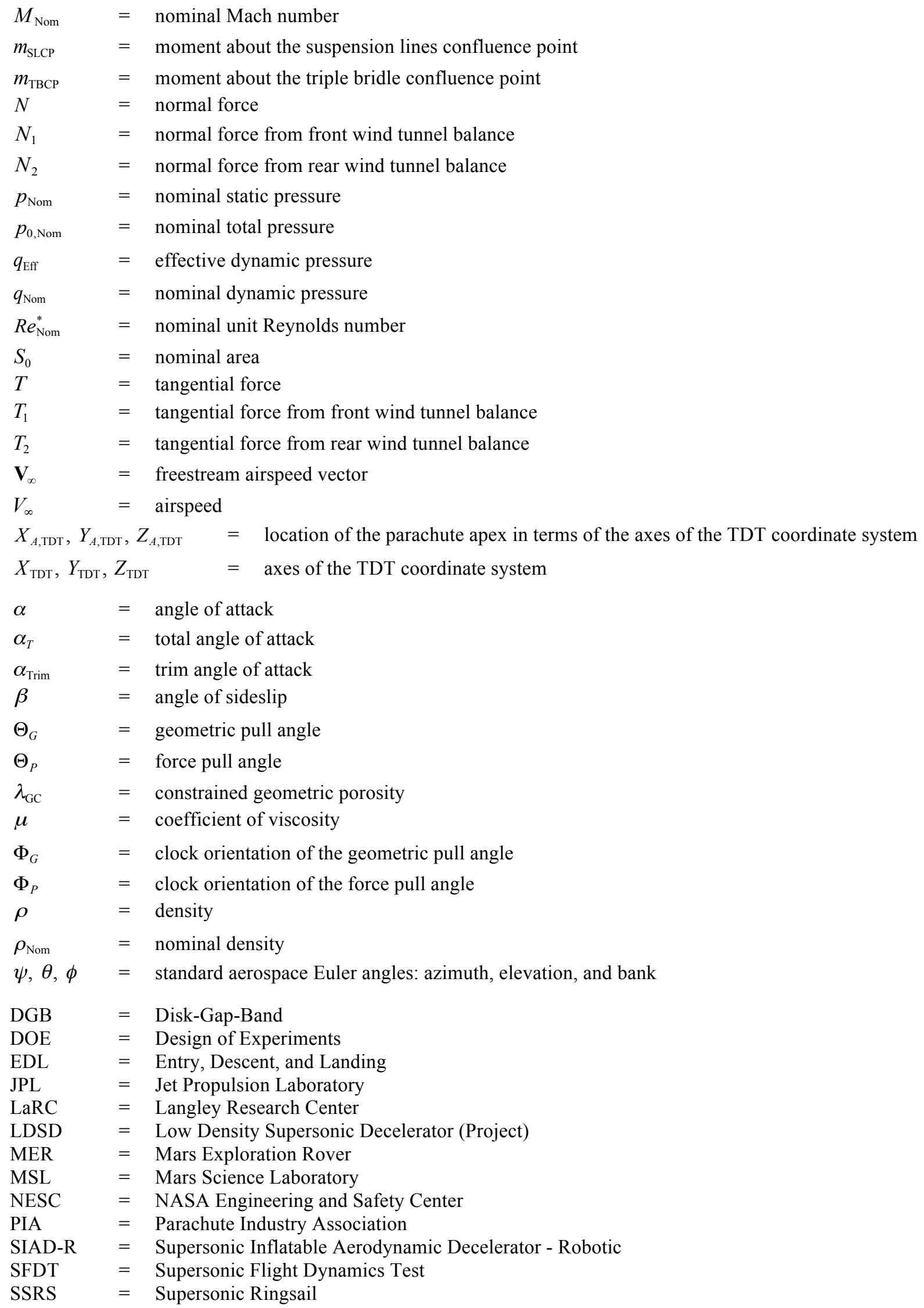




\section{Introduction}

$\mathrm{T}$ HE Low-Density Supersonic Decelerators (LDSD) Project advanced the development of a new, large-diameter supersonic Ringsail parachute (SSRS) for use during entry, descent, and landing (EDL) at Mars. This development included a set of supersonic/subsonic flight tests in the Earth's atmosphere known as the Supersonic Flight Dynamics Test(s), or SFDT ${ }^{1}$. For the SSRS parachute to be adopted by a future mission to Mars, a database of its aerodynamic characteristics needs to be available for flight dynamics simulations. The LDSD Project team identified a gap in the parachute aerodynamic database that could not be sufficiently filled by the planned SFDT, namely the drag and static aerodynamic coefficients (i.e., $C_{D}$ and $C_{T}, C_{N}, C_{m}$ ) at subsonic speeds. After discussing the available options, the LDSD Project team concluded that a subsonic wind tunnel test using subscale models, similar to that conducted in 2001 for the Mars Exploration Rover (MER) parachute ${ }^{2}$, was the best and most cost effective way to fill this gap in the aerodynamic database. The Mars Science Laboratory (MSL) Disk-Gap-Band (DGB) parachute ${ }^{3}$ was included as part of the test to provide a basis for direct comparison between the Ringsail parachute and current Mars parachute technology. In addition, capturing the dynamic motions of both parachute types was considered to be important, as it would provide data for future improvement of parachute aerodynamic models (e.g., for the creation of dynamic aerodynamic coefficient models which are not currently accounted for in flight dynamic simulations).

The following principal goals were defined for this test:

1) Obtain SSRS and DGB parachute aerodynamic data that would allow for the creation of models to simulate the dynamics of payloads descending at subsonic speeds at Mars.

2) Obtain data that will allow comparisons to be made between the performance of the new SSRS parachute and the heritage DGB parachute.

The test was conducted at the NASA Langley Research Center (LaRC) Transonic Dynamics Tunnel (TDT). The SSRS parachute models were fabricated to a scale of 5.0\% (5.00 ft nominal diameter). The DGB parachute models were fabricated to a scale of $6.7 \%$ ( $4.70 \mathrm{ft}$ nominal diameter). Fabric permeability has a significant effect on the aerodynamic performance of a parachute. To capture the effect of fabric permeability, and allow for interpolation of the test results for Mars flight conditions, the model parachutes (both for SSRS and DGB types) were fabricated from two types of fabrics: "standard" permeability and "low" permeability. The effective permeability of the materials used in current Mars canopies at Mars flight conditions lies between those of the "standard" and "low" fabrics at the wind tunnel test conditions. Forebody models were placed upstream of the parachute models to create aerodynamic wakes to impinge on the parachute models, as is the case in the full-scale parachute/forebody combinations.

Two test setups were used, one to determine the drag coefficients and dynamic motions and another to determine the static coefficients. In the drag coefficients and dynamic motions test setup, the parachutes were attached to a wind tunnel balance at their upstream end, but otherwise allowed to fly freely. In this test setup, the principal measurements were the components of the force vector generated by the parachute (and measured by the front wind tunnel balance), and the motion of the parachute as determined from a high-speed video camera. In the static coefficients test setup a rear test fixture was added to fix the vertical position of the parachute apex. Both the front and rear test fixtures were attached to a turntable used to control the parachute's angle of attack. The rear test fixture had its own wind tunnel balance. Combining the forces measured by the front and rear wind tunnel balances allowed for the calculation of the static coefficients.

Data were obtained at a wide variety of test conditions (i.e., Mach numbers and test static pressures) and processed to yield the following results for all parachute/fabric combinations: drag coefficients, total force coefficients, static coefficients, dynamic motions (synchronized force vector components and parachute apex location), and inflated parachute geometry. A limited set of drag and static coefficients results were obtained for reefed SSRS parachutes.

This paper describes the test setup and conditions, how the results were analyzed, and presents and discusses a sample of the results. The test setup, model parachutes, and test conditions are described in Section II. The methods used to analyze the drag, static, and dynamic motions data are described in Section III. Section IV presents a sample 
of the results obtained for the drag coefficients, static coefficients, and dynamic motions tests. Finally, conclusions are provided in Section V.

\section{Test Setup and Execution}

In this section, the test setup and execution are briefly described. The principal purpose of these descriptions is to provide information required for understanding the data analyses and results.

\section{A. Wind Tunnel}

The test was conducted at the TDT, seen in Fig. 1, located at NASA LaRC. Three key characteristics made the TDT particularly suitable for this test:

1) Test section: slotted, 16 - by 16 -ft with cropped corners. The test section is of sufficient size to allow testing of reasonably-sized model parachutes $(\geq 5 \%$ scale) that closely resemble their full-scale counterparts, without excessive blockage of the test section. The slots reduce blockage and allow for the testing of larger model parachutes (as compared to a test section with solid walls of the same size).

2) Operating pressure: 0.03 to $1 \mathrm{~atm}$. The TDT can operate at very low pressures and densities. This feature allows for a better simulation of the low-density Mars flight environment. In addition, operating at low pressures allows the model parachutes to be tested at high subsonic Mach numbers $(M \sim 0.5$ for the present test) while keeping the dynamic pressure within the limits required to maintain the structural integrity of the model parachutes and test fixture.

3) Operating Mach number: 0 to 1.2. The Mach number range of the TDT allows for testing the model parachutes from low subsonic speeds $(M \sim 0.09)$ to high subsonic speeds $(M \sim 0.5)$. Most of the parachute phase during recent missions to Mars (e.g., MER, MSL) is spent at Mach numbers below 0.6.

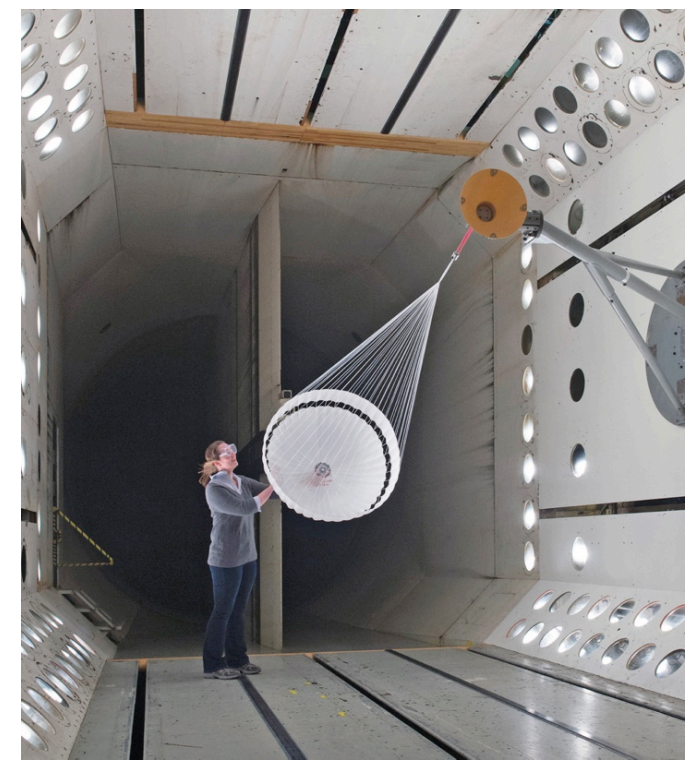

Figure 1. TDT Test Section with Model Parachute

\section{B. Parachute and Forebody Models}

Two parachute/forebody models were used in this test: the SSRS parachute with the Supersonic Inflatable Aerodynamic Decelerator - Robotic (SIAD-R) forebody, and the DGB parachute with the MSL backshell.

Fabric permeability has a significant effect on the aerodynamic performance of a parachute. To capture the effect of fabric permeability, and allow for interpolation of the test results to Mars flight conditions, the model parachutes (both for SSRS and DGB types) were fabricated from two types of fabrics: "standard" permeability and "low" permeability. The "standard" permeability fabric used was PIA-C-7020D Type I, per Parachute Industry Association (PIA) specification ${ }^{4}$. For the model parachutes in this test, the PIA-C-7020D Type I fabric used was international 
orange ${ }^{*}$ in color. The "low" permeability fabric used was PIA-C-44378D Type I, per PIA specification". For the model parachutes in this test, the PIA-C-44378D Type I fabric was white in color. With an estimate of the fabric permeability at Mars operating conditions, ${ }^{\dagger}$ the results obtained during the present test for the same canopy type (SSRS or DGB) and test condition can be interpolated to predict the parachute's aerodynamic performance at Mars. Note: the interpolation required for predicting the aerodynamic performance of parachutes at Mars is not part of the work completed for this study, and is not included in this paper.

In both the SSRS and DGB parachute models, the vent lines terminated at a 1-inch inner-diameter ring. During the static coefficients test, this ring served to attach a brass bushing that allowed the canopy apex to slide freely along a load rod connected to the balance measuring loads at the parachute apex. During the drag coefficients and dynamic motions tests, flow through the center of the 1-inch vent ring was obstructed by a vent plug to preserve the same vent area across the different test setups. In addition, the vent plug provided a surface on which to attach a photometric target at the canopy apex. This target was used for tracking the parachute dynamic motions.

\section{SSRS Parachute and SIAD-R Forebody Models}

The SSRS model parachutes were a 5.0\% scale (nominal) representation of the full-scale SSRS parachute as flown in SFDT-2 (see Fig. 2). The nominal diameter $\left(D_{0}\right)$ and area $\left(S_{0}\right)$ of the model parachutes were $5.00 \mathrm{ft}$ and $19.66 \mathrm{ft}^{2}$, respectively. The nominal constrained geometric porosity $\left(\lambda_{\mathrm{GC}}\right)$ of the model parachutes was $15 \%$. The constraint is caused by the crossing of the radial lines at the vent, which does not allow the vent to achieve its maximum possible diameter. The number of suspension lines used in the model parachutes was 48 - half the number of suspension lines used in the full-scale parachute (i.e., 96). Using 96 suspension lines for the $5.0 \%$ scale model parachutes would have made their fabrication difficult, as well as unduly stiffening them. Four SSRS model parachutes were available for testing. Two model parachutes were fabricated using PIA-C-7020D Type I fabric; the other two were fabricated using PIA-C-44378D Type I fabric.

The forebody model was built to the same scale as the model parachutes, and had a maximum diameter $\left(D_{F}\right)$ of 11.81 inches. This forebody model simulated the SFDT-2 test vehicle with SIAD-R deployed. The parachute and forebody models were geometrically similar to those of the full-scale SFDT-2 test vehicle. The trailing distance ratio (i.e., distance from the parachute skirt to the maximum forebody diameter) was approximately 9.8 (see Fig. 2).

The SSRS parachutes were also tested in a reefed configuration. Reefing was effected by running a cord of the desired length through the suspension lines' attachment loops at the canopy skirt.

\footnotetext{
* The fabric color choices were based on material availability and to make it easier to differentiate between parachutes fabricated from PIA-C-7020D Type I and PIA-C-44378D Type I fabrics. Color does not have an effect on the fabric properties.

${ }^{\dagger}$ Fabric permeability varies with operating/test condition, in particular with respect to the pressure difference across the fabric.
} 


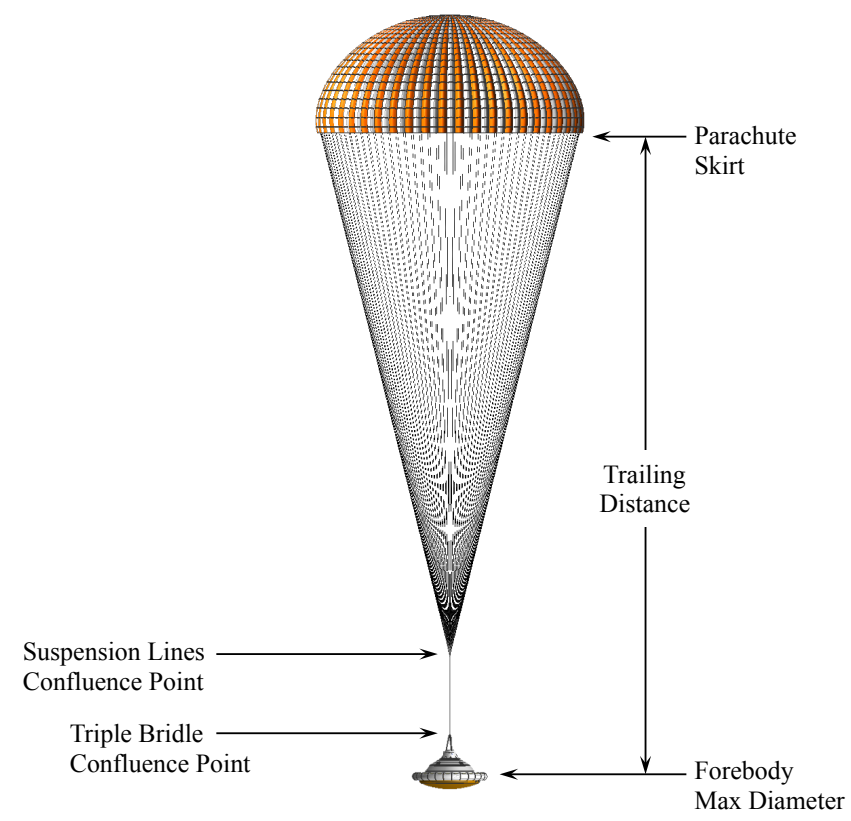

Figure 2. SSRS Parachute and SIAD-R Forebody Overall Geometry

\section{DGB Parachute and MSL Forebody Models}

The DGB model parachutes were a 6.7\% scale (nominal) representation of the full-scale DGB parachute flown by the MSL Mission (see Fig. 3). The nominal diameter and area of the model parachutes were $4.70 \mathrm{ft}$ and $17.32 \mathrm{ft}^{2}$, respectively. The nominal constrained geometric porosity of the model parachutes was $12.85 \%$. The number of suspension lines used in the model parachutes was 40 - half the number of suspension lines used in the full-scale parachute (i.e., 80). Using 80 suspension lines for the $6.7 \%$ scale model parachutes would have made their fabrication difficult, as well as unduly stiffening them. Four DGB model parachutes were available for testing. Two model parachutes were fabricated using PIA-C-7020D Type I fabric; the other two were fabricated using PIA-C-44378D Type I fabric.

The forebody model was built to the same scale as the parachute. For $M<0.5$, MSL had released its heatshield, and the only portion of the aeroshell remaining attached to the parachute was the backshell. This forebody configuration (i.e., backshell-only) was used during the test. The forebody model had a maximum diameter of 11.70 inches. The parachute and forebody models were geometrically similar to those of the full-scale MSL. The trailing distance ratio (i.e., distance from the parachute skirt to the maximum forebody diameter) was approximately 10.3 (see Fig. 3). 


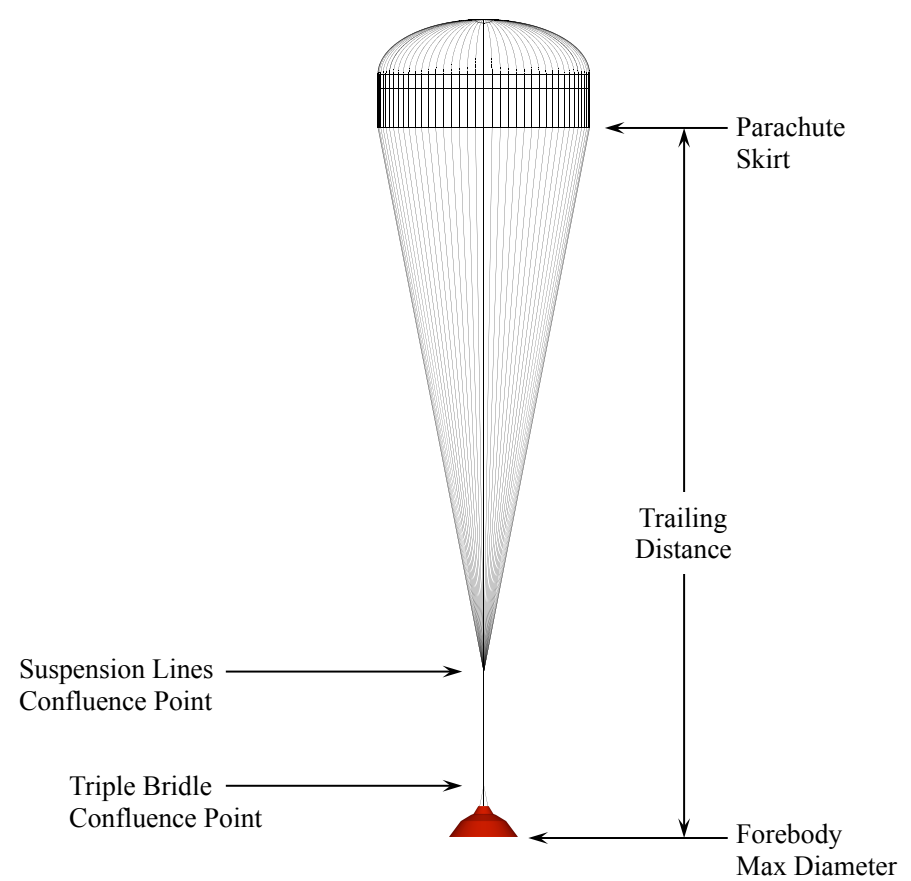

Figure 3. DGB Parachute and MSL Forebody (Backshell) Overall Geometry

\section{Drag Coefficients and Dynamic Motions Test Setup}

The drag coefficients and dynamic motions test setup is shown in Fig. 4 with a DGB parachute and MSL forebody. The parachute was connected to the wind tunnel balance through a riser. Along this riser was a swivel that allowed the parachute to spin without twisting the suspension lines. The wind tunnel balance (behind the forebody, not visible in Fig. 4) was capable of measuring three orthogonal force components. The force measurements from the wind tunnel balance allowed for the determination of the drag force (force parallel to the freestream airspeed vector) and the total force vector components (in the wind tunnel coordinate system described in a following section). Surrounding the wind tunnel balance was a windshield that prevented aerodynamic forces on the balance from affecting its force measurements. The forebody model was mounted onto the wind tunnel windshield, so that the aerodynamic forces on the forebody were not measured by the balance. The wind tunnel balance was mounted to the front test fixture. In turn, the front test fixture was connected to the turntable on the side of the wind tunnel. During drag coefficients and dynamic motions testing the turntable remained in a fixed position. Note that the parachute was free to oscillate, pivoting about its upstream attachment to the wind tunnel balance. This attachment point was located about a point that was equivalent to the triple bridle confluence point shown in Figs. 2 and 3.

High-speed and high-definition video cameras were mounted on the wind tunnel sting behind the parachute as can be seen in Fig. 4. These cameras were used to track the parachute apex in order to determine the parachute's dynamic motions. Synchronization between the video cameras and the TDT numerical data stream was accomplished by the firing of an electronic flash through the windows of the tunnel into the test section. Firing of the flash was recorded in one of the channels in the TDT numerical data stream. At the same time, the flash could be seen on the video. Aligning the flash firings on both data streams (video and TDT numerical data) allowed for their synchronization. 


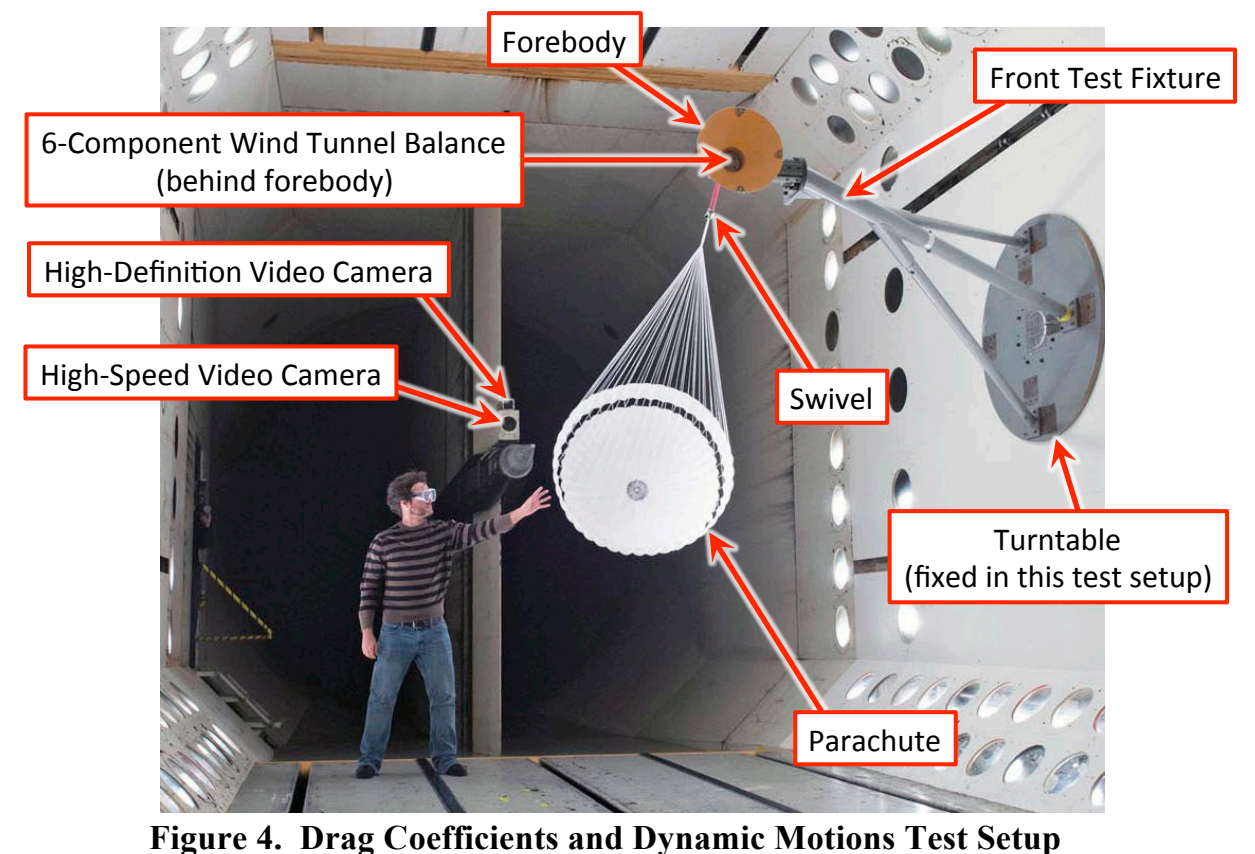

\section{Static Coefficients Test Setup}

The static coefficients test setup is shown in Fig. 5 with an SSRS parachute and SIAD-R forebody. The upstream portion of the static coefficients test setup (i.e., parachute riser, swivel, front wind tunnel balance, forebody, and front test fixture) was the same as that for the drag coefficients and dynamic motions test setup (see previous section). In addition, a rear test fixture, rear wind tunnel balance, and load rod allowed the measurement of forces at the apex of the parachute. The apex of the parachute had a load rod bushing attached to it. This bushing slid along the load rod. Forces at the apex of the parachute were transmitted to the rear balance through the load rod. Permitting the parachute apex to slide fore and aft along the load rod allowed the parachute to take its natural inflated shape. Only a few inches of the load rod protruded into the canopy. A close-up image of the test setup in the apex of the parachute is shown in Fig. 6. The rear balance was attached to the rear test fixture, which in turn was attached to the turntable. The desired parachute angle of attack was enforced on the by remotely rotating the turntable. Note that the forebody, being fixed to the front test fixture, also rotated. The range of angles of attack used during this test was $\pm 17^{\circ}$. 


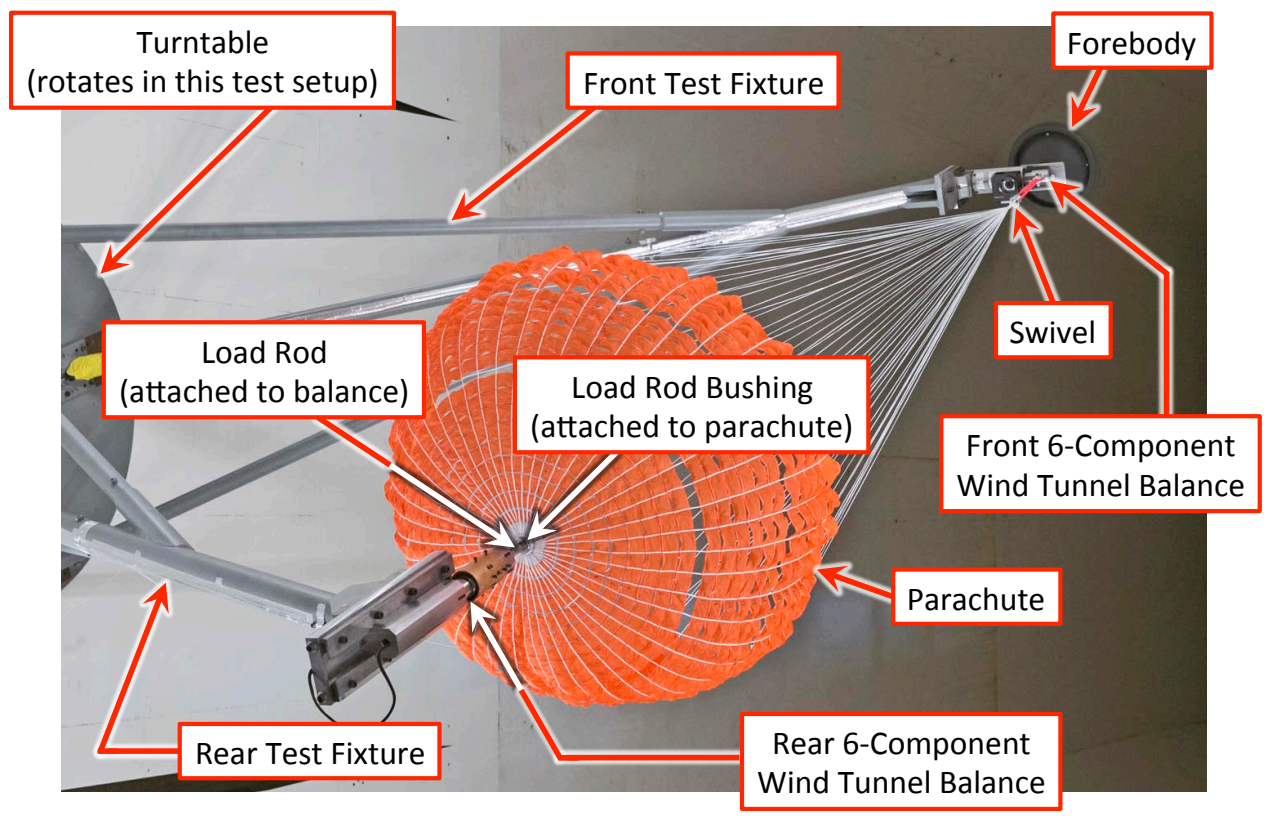

Figure 5. Static Coefficients Test Setup

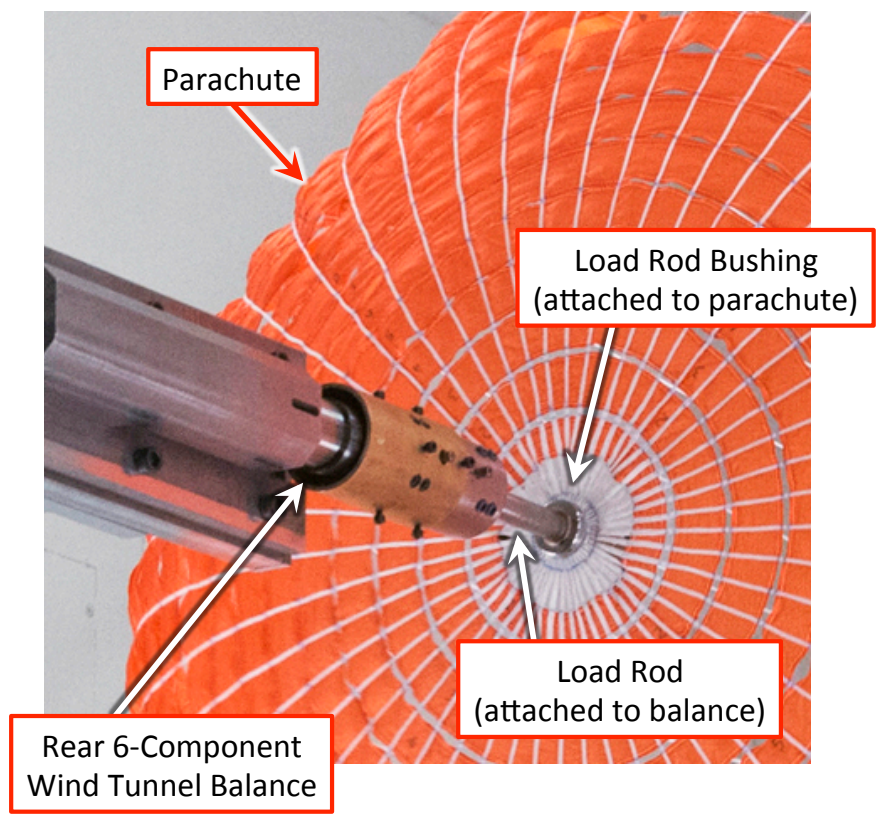

Figure 6. Close-up of the Static Coefficients Test Setup at the Apex of the Parachute

\section{E. Nominal Test Conditions}

A set of nominal test conditions was defined through various criteria, including the Design of Experiments (DOE) methods. The principal objectives in setting test conditions were to allow for the determination of results' sensitivities with respect to operating conditions (e.g., Mach number, unit Reynolds number, mass ratio), and to allow for future interpolation of the results to Mars flight conditions. Thirteen nominal test conditions were specified; they are listed in Table 1, sorted by static pressure ( $\left.p_{\text {Nom }}\right)$ from high to low. It was the intention to test all parachute type (SSRS and DGB) and fabric (PIA-C-7020D Type I and PIA-C-44378D Type I) combinations at all nominal test conditions, for all three types of tests (i.e., drag coefficients, dynamics motions, and static coefficients). For the most part this was achieved, with the following exceptions. Nominal test condition 8 was abandoned after an initial trial where the low dynamic pressure at this nominal test condition rendered the results unreliable. The 
objective of this nominal test condition was to obtain data matching the value of the unit Reynolds number ( $\left.R e_{\text {Nom }}^{*}\right)$ during subsonic flight at Mars. ${ }^{\star}$ For drag coefficients and dynamic motions testing, the SSRS/PIA-C-44378D Type I combination's tendency to fly at high angles of attack made it inadvisable to test at the highest dynamic pressure ( $q_{\text {Nom }}=25$ psf ) because there was a significant risk of overloading some of the components of the front balance. Thus, for SSRS/PIA-C-44378D Type I parachutes, no drag coefficient or dynamic motions data were collected for nominal test conditions 3,6 , and 11 .

Table 1. Nominal Test Conditions

\begin{tabular}{|c|c|c|c|c|c|c|}
\hline Nominal & $\begin{array}{c}\text { Mach } \\
\text { number }\end{array}$ & $\begin{array}{l}\text { Dynamic } \\
\text { pressure }\end{array}$ & $\begin{array}{c}\text { Unit Reynolds } \\
\text { number }\end{array}$ & $\begin{array}{c}\text { Static } \\
\text { pressure }\end{array}$ & $\begin{array}{c}\text { Total } \\
\text { pressure }\end{array}$ & Density \\
\hline Test Condition & $M_{\mathrm{Nom}}$ & $\begin{array}{l}q_{\mathrm{Nom}} \\
(\mathrm{psf})\end{array}$ & $\begin{array}{c}\operatorname{Re}_{\text {Nom }}^{*} \\
\left(\mathrm{ft}^{-1}\right)\end{array}$ & $\begin{array}{l}p_{\mathrm{Nom}} \\
(\mathrm{psf})\end{array}$ & $\begin{array}{l}p_{0, \mathrm{Nom}} \\
\text { (psf) }\end{array}$ & $\begin{array}{c}\rho_{\mathrm{Nom}} \\
\left(\mathrm{slug} / \mathrm{ft}^{3}\right)\end{array}$ \\
\hline 1 & 0.087 & 11.11 & $5.59 \cdot 10^{5}$ & 2116.29 & 2127.42 & $2.206 \cdot 10^{-3}$ \\
\hline 2 & 0.106 & 16.67 & $6.86 \cdot 10^{5}$ & 2116.29 & 2133.01 & $2.208 \cdot 10^{-3}$ \\
\hline $3^{(\mathrm{a})}$ & 0.130 & 25.00 & $8.41 \cdot 10^{5}$ & 2116.29 & 2141.40 & $2.210 \cdot 10^{-3}$ \\
\hline 4 & 0.110 & 11.11 & $4.42 \cdot 10^{5}$ & 1320.00 & 1331.14 & $1.377 \cdot 10^{-3}$ \\
\hline 5 & 0.165 & 16.67 & $4.42 \cdot 10^{5}$ & 874.00 & 890.78 & $9.147 \cdot 10^{-4}$ \\
\hline $6^{(\mathrm{a})}$ & 0.250 & 25.00 & $4.42 \cdot 10^{5}$ & 571.43 & 596.82 & $6.022 \cdot 10^{-4}$ \\
\hline 7 & 0.250 & 16.67 & $2.94 \cdot 10^{5}$ & 380.00 & 396.93 & $4.005 \cdot 10^{-4}$ \\
\hline $8^{(\mathrm{b})}$ & 0.098 & 2.00 & $8.93 \cdot 10^{4}$ & 299.32 & 301.33 & $3.122 \cdot 10^{-4}$ \\
\hline 9 & 0.324 & 21.61 & $2.98 \cdot 10^{5}$ & 294.01 & 316.19 & $3.125 \cdot 10^{-4}$ \\
\hline 10 & 0.250 & 9.40 & $1.66 \cdot 10^{5}$ & 214.75 & 224.30 & $2.263 \cdot 10^{-4}$ \\
\hline $11^{(\mathrm{a})}$ & 0.500 & 25.00 & $2.31 \cdot 10^{5}$ & 142.86 & 169.46 & $1.561 \cdot 10^{-4}$ \\
\hline 12 & 0.400 & 13.50 & $1.53 \cdot 10^{5}$ & 120.54 & 134.58 & $1.295 \cdot 10^{-4}$ \\
\hline 13 & 0.500 & 17.94 & $1.66 \cdot 10^{5}$ & 102.54 & 121.63 & $1.121 \cdot 10^{-4}$ \\
\hline
\end{tabular}

(a) This condition was omitted for SSRS/PIA-C-44378D Type I parachutes during drag and dynamic motions tests.

(b) This condition was omitted for all parachute models and test setups.

Table 1 lists the nominal test conditions. Nominal has a specific meaning in this paper. A nominal test condition is a targeted, freestream, test condition, as determined by the built-in TDT instrumentation. By targeted it is meant that a best effort was conducted to reach the specific nominal test condition values of Mach number and dynamic pressure, but small deviations were allowed. It can be time-consuming to achieve the desired Mach number and dynamic pressure within small tolerances, and for the present test such small tolerances were unnecessary. It was significantly more important to know the test conditions achieved during a specific data collection interval.

By freestream it is meant that the nominal test conditions were measured as they existed upstream of the parachute/forebody model. The parachute, forebody, and test fixture partially blocked the test section. As a result of the blockage, test conditions at the parachute/forebody model were different than those upstream (i.e., freestream). This blockage increased the local dynamic pressure at the parachute canopy by about $6 \%$ and caused associated changes in other test parameters (e.g., Mach number). Corrections of the test parameters for blockage were performed during post-test analyses, but were not taken into consideration while conducting the test.

\footnotetext{
* Here, as elsewhere in this paper, it is the unit Reynolds number, $R e^{*}=\rho V_{\infty} / \mu$, that is of interest. The subscale model parachutes are fabricated from full-scale fabric materials - the fabric cannot be scaled. Thus, the characteristic lengths of the fabric (e.g., fabric pore size, yarn size, thickness) have the same value for the full-scale and model parachutes. Viscous effects at the scale of the fabric affect fabric permeability. Thus, Reynolds number, based on the fabric scale length, is a relevant parameter. Since the fabric scale length is the same for the full-scale and subscale model parachutes, the unit Reynolds number is a good parameter for evaluating the subscale wind tunnel test results. Doing so avoids the problem of having to determine the appropriate value of the fabric characteristic length.

Full-scale and subscale parachutes operate in a highly separated flow environment where skin friction and issues associated with boundary layers are of limited importance. Because of this, a Reynolds number defined using overall parachute dimensions (such as its nominal diameter) as its reference length is not particularly useful as a dimensionless parameter for understanding the aerodynamic behavior of parachutes.
} 
Finally, the test was conducted setting the nominal test conditions using the built-in TDT instrumentation (i.e., total pressure, static pressure, and total temperature). At the low dynamic pressures at which the test was conducted, the built-in TDT instrumentation was not as accurate as desired. Thus, a test-specific pitot-static tube and pressure transducers were used to determine the actual test conditions. The difference between the freestream test condition, as calculated by the built-in TDT instrumentation and the pitot-static tube pressure sensors, were sufficiently small (within a few percent) to ignore while the test was being conducted, but significant enough to take into consideration during data analyses.

\section{Data Analyses}

\section{A. Test Conditions}

Test conditions were calculated by applying the isentropic flow equations. Data used in the calculations were obtained from the built-in TDT instrumentation and the pressure sensors connected to the test-specific pitot-static tube. In addition, a blockage correction was implemented based on data obtained during the MER parachute wind tunnel test ${ }^{1}$. Test conditions with the blockage correction incorporated are labeled as effective test conditions since they best represent the conditions experienced by the parachute canopy. The effective dynamic pressure, $q_{\text {Eff }}$, was used in the calculation of the aerodynamic coefficients.

\section{B. Drag and Total Force Coefficients}

The drag $\left(C_{D}\right)$ and total $\left(C_{\text {Tot }}\right)$ force coefficients are defined by:

$$
\begin{gathered}
C_{D}=\frac{\text { Drag Force }}{q_{\mathrm{Eff}} S_{0}} \\
C_{\text {Tot }}=\frac{\text { Total Force }}{q_{\mathrm{Eff}} S_{0}}
\end{gathered}
$$

The "Drag Force" was the component of the force measured by the front wind tunnel balance parallel to the freestream airspeed vector. The "Total Force" was the magnitude of the force vector measured by the front wind tunnel balance. Note that both coefficients use the nominal area, $S_{0}$, as the reference area.

\section{Static Coefficients}

A side view of the static coefficients test setup is shown in Fig. 7. In this figure the turntable has been rotated so that the parachute is at an angle of attack, $\alpha$, relative to the freestream airspeed vector, $\mathbf{V}_{\infty}$. The quantities $T_{1}$ and $N_{1}$ were the tangential and normal forces measured by the front wind tunnel balance, respectively. The quantities $T_{2}$ and $N_{2}$ were the tangential and normal forces measured by the rear wind tunnel balance, respectively. Measurements of the riser length ( $L_{\text {Riser }}$ ) and total length ( $L_{\text {Tot }}$ ) were available. With these quantities, the tangential force, $(T)$, normal force $(N)$, pitching moment about the suspension lines confluence point $\left(m_{\text {SLCP }}\right)$, and pitching moment about the triple bridle confluence point $\left(m_{\mathrm{TBCP}}\right)$ were calculated from:

$$
\begin{gathered}
T=T_{1}+T_{2} \\
N=N_{1}+N_{2} \\
m_{\mathrm{SLCP}}=N_{1} L_{\text {Riser }}-N_{2}\left(L_{\text {Tot }}-L_{\text {Riser }}\right) \\
m_{\mathrm{TBCP}}=-N_{2} L_{\text {Tot }}
\end{gathered}
$$


The pitching moments $m_{\mathrm{SLCP}}$ and $m_{\mathrm{TBCP}}$ are defined as positive nose-up. Because the parachute was allowed to slide freely along the load rod (see Fig. 6), $T_{2}$ was much smaller than $T_{1}$. The associated tangential ( $C_{T}$ ), normal $\left(C_{N}\right)$, and pitching moment ( $C_{m, \mathrm{SLCP}}$ and $\left.C_{m, \mathrm{TBCP}}\right)$ static aerodynamic coefficients are defined by:

$$
\begin{gathered}
C_{T}=\frac{T}{q_{\mathrm{Eff}} S_{0}} \\
C_{N}=\frac{N}{q_{\mathrm{Eff}} S_{0}} \\
C_{m, \mathrm{SLCP}}=\frac{m_{\mathrm{SLCP}}}{q_{\mathrm{Eff}} S_{0} D_{0}} \\
C_{m, \mathrm{TBCP}}=\frac{m_{\mathrm{TBCP}}}{q_{\mathrm{Eff}} S_{0} D_{0}}
\end{gathered}
$$

Note that all static coefficients use the nominal area, $S_{0}$, as the reference area, and the nominal diameter, $D_{0}$, as the reference length.

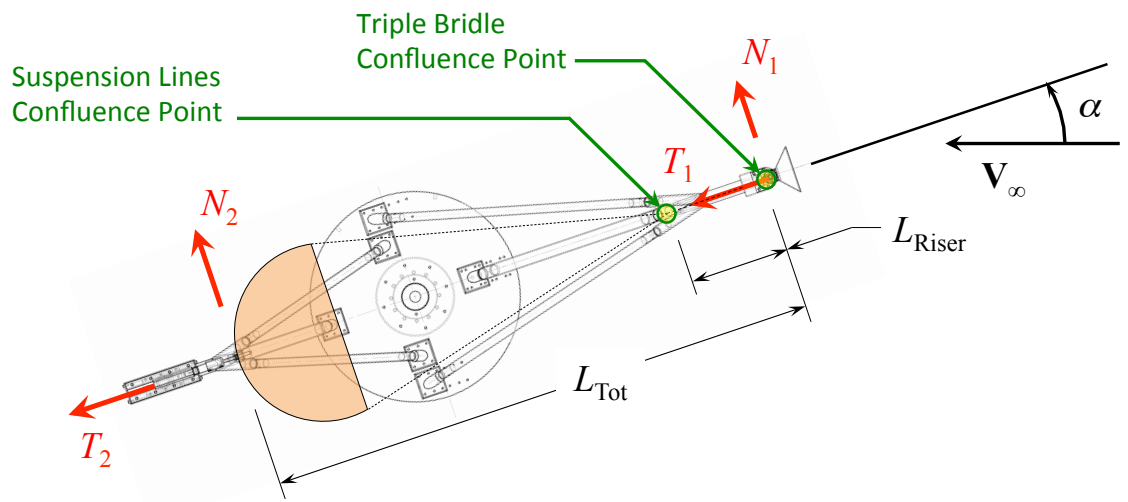

Figure 7. Definition of Static Forces and Parachute System Lengths

Static coefficient testing was conducted with angle of attack, $\alpha$, sweeps from $-17^{\circ}$ to $17^{\circ}$. From symmetry considerations, $C_{T}$ should be an even function with respect to $\alpha$, and $C_{N}, C_{m, \mathrm{SLCP}}$, and $C_{m, \mathrm{TBCP}}$ should be odd functions with respect to $\alpha$. With small deviations, the expected symmetry is reflected in the raw static coefficient test results. Additional processing of the static coefficients was performed to enforce the expected symmetries and create smooth curves for $C_{T}, C_{N}, C_{m, \mathrm{SLCP}}$, and $C_{m, \mathrm{TBCP}}$ versus $\alpha$. Also from symmetry considerations, the static aerodynamic coefficients can be expressed as functions of the total angle of attack, $\alpha_{T} \geq 0^{\circ}$, where the normal force lies in the plane defined by the axis of symmetry of the parachute and the airspeed vector, and the pitching moments are normal to this plane. Note that $\alpha_{T}=|\alpha|$ when the angle of sideslip, $\beta$, is zero. In all discussions in this paper it is assumed that $\beta=0$.

An important quantity for understanding parachute behavior are the values of the trim angles of attack, $\alpha_{\text {Trim }}$. Of particular interest are the trim angles of attack that are stable. The trim angle of attack definition used in this report is the value of $\alpha$ for which $C_{m, \mathrm{SLCP}}=0$ (a similar definition can be made using $C_{m, \mathrm{TBCP}}$ ). A trim angle of attack is unstable if $\left(d C_{m, S L C P} / d \alpha\right)>0$ at $\alpha=\alpha_{\text {Trim }}$. A trim angle of attack is stable if $\left(d C_{m, S L C P} / d \alpha\right)<0$ at $\alpha=\alpha_{\text {Trim }}$. If $\left(d C_{m, S L C P} / d \alpha\right)=0$ at $\alpha=\alpha_{\text {Trim }}$ the trim point is neutral. In Fig. 8, a plot of $C_{m, \text { SLCP }}$ versus $\alpha$ is shown for an SSRS parachute using PIA-C-7020D Type I fabric being tested at nominal test condition 13 ( $M_{\text {Nom }}=0.500$, $q_{\text {Nom }}=17.94 \mathrm{psf}$ ). Three trim angles of attack can be identified: $\alpha_{\text {Trim }}=0^{\circ}$ (unstable) and $\alpha_{\text {Trim }}= \pm 5.3^{\circ}$ (stable). 
The behavior shown in Fig. 8 is typical for parachutes with axisymmetric canopies. Because of symmetry there is a trim angle of attack at zero degrees angle of attack. This trim angle of attack is usually unstable. As the magnitude of the angle of attack is increased, a stable trim angle of attack is usually found. There can be additional trim angles of attack as the angle of attack continues to increase. Stable and unstable trim angles of attack alternate with increases in angle of attack.

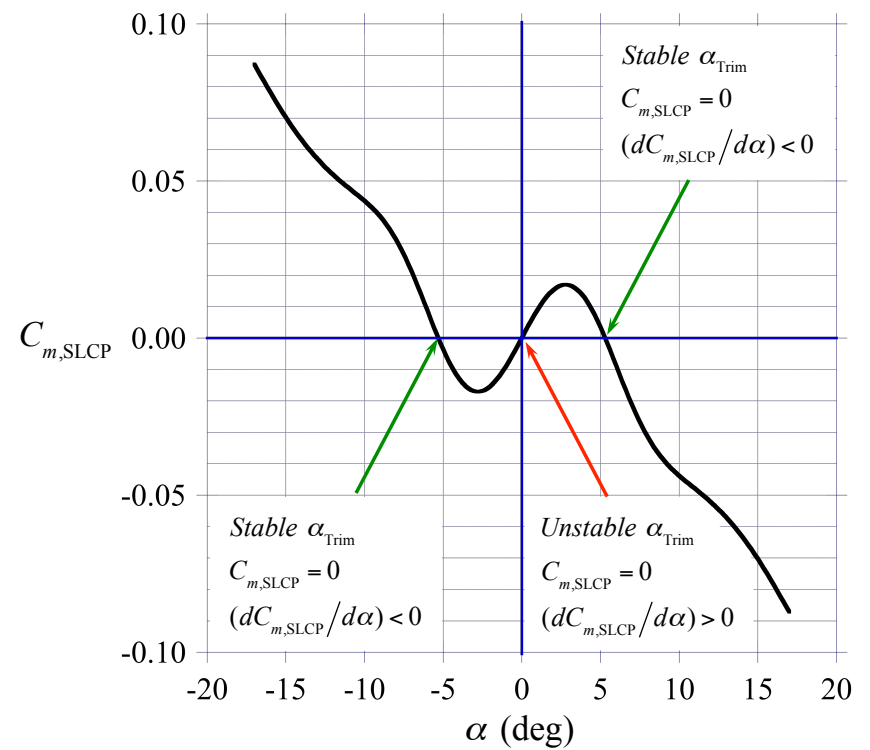

Figure 8. Example $C_{m, \mathrm{SLCP}}$ versus $\alpha$ Curve Illustrating $\alpha_{\text {Trim }}$

\section{Dynamic Motions}

The dynamics motions data is divided into two streams: those obtained from the front wind tunnel balance (forces), and those obtained from the high-speed video camera (position). These data streams were synchronized using the flash-based procedure described previously, and time history records for the dynamic motions were 60 to 75 seconds long.

In this paper, statistics of the dynamic motions are used to characterize the general behavior of the parachutes. At a later date, it is expected that the dynamics motion data will be used to improve the parachute aerodynamics models by, for example, allowing for the creation of dynamic aerodynamic models (i.e., models that are rate dependent).

\section{Force Dynamic Motions}

The force vector obtained from the front wind tunnel balance (at a sample rate of $600 \mathrm{~Hz}$ ) was decomposed into three components with a tunnel-aligned coordinate system. This coordinate system (known as the TDT coordinate system) has its origin at the triple bridle confluence point (i.e., the attachment point of the parachute to the wind tunnel balance). The axes of the TDT coordinate system are $X_{\mathrm{TDT}}, Y_{\mathrm{TDT}}$, and $Z_{\mathrm{TDT}}$. These axes form a right-handed orthogonal coordinate system. The $X_{\text {TDT }}$ axis points directly upstream, parallel to the tunnel's test section. The $Y_{\text {TDT }}$ axis points to the right (as seen when looking upstream). The $Z_{\mathrm{TDT}}$ axis points down. The force components associated with these axes are $F_{X \text {,TDT }}, F_{Y, \mathrm{TDT}}$, and $F_{Z, \mathrm{TDT}}$, respectively. Notice that because of the direction of the $X_{\mathrm{TDT}}$ axis, $F_{X \text {,TDT }}$ will always be negative $\left(F_{X \text {,TDT }}=-\right.$ Drag Force $)$. From the force components two relevant angles were calculated: the force pull angle, $\Theta_{P}$, and the clock orientation of the force pull angle, $\Phi_{P}$. The force pull angle is the angle between the negative $X_{\mathrm{TDT}}$ direction and the total force vector, $\mathbf{F}_{\text {Tot }}$, with magnitude $F_{\text {Tot }}$. Thus,

$$
\begin{gathered}
F_{\mathrm{Tot}}=\sqrt{F_{X, \mathrm{TDT}}^{2}+F_{Y, \mathrm{TDT}}^{2}+F_{Z, \mathrm{TDT}}^{2}} \\
\Theta_{P}=\arccos \left(\frac{-F_{X, \mathrm{TDT}}}{F_{\mathrm{Tot}}}\right) \quad 0 \leq \Theta_{P} \leq \pi
\end{gathered}
$$


The clock orientation of the force pull angle is defined by:

$$
\Phi_{P}=\arctan \left(\frac{F_{Y, \mathrm{TDT}}}{F_{Z, \mathrm{TDT}}}\right) \quad-\pi<\Phi_{P} \leq \pi
$$

Figure 9 graphically shows the definitions of $\Theta_{P}$ and $\Phi_{P}$. Notice that the arctan function used in Equation (13) retains the quadrant information (i.e., atan2 in most software).
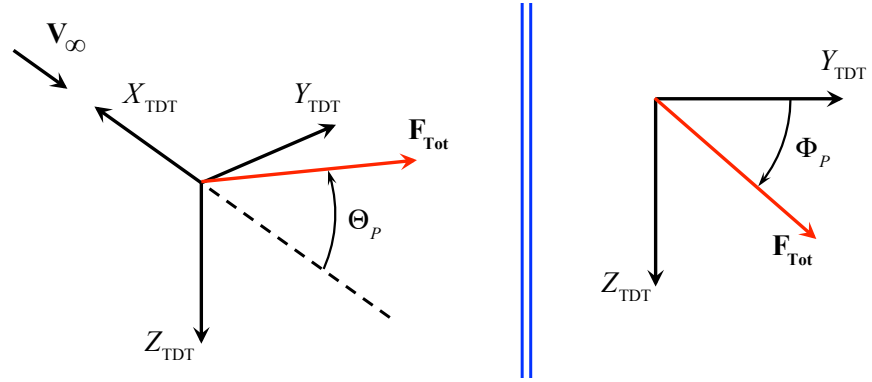

Figure 9. Definition of $\Theta_{P}$ and $\Phi_{P}$

The force pull angle, $\Theta_{P}$, is an important metric for parachute behavior since it indicates to what extent the parachute is pulling sideways on the payload. What has been described above is the calculation of the time history of $\Theta_{P}$. In later sections, the statistics of $\Theta_{P}$ (e.g., its median and $95^{\text {th }}$ percentile value over 60 to 75 seconds) will be used to characterize the parachute's behavior.

\section{Position Dynamic Motions}

The position of the parachute apex was observed by the high-speed video camera at a frequency of $120 \mathrm{~Hz}$. These video data were used to obtain the geometric position of the parachute apex in the tunnel coordinate system: $X_{A, \mathrm{TDT}}, Y_{A, \mathrm{TDT}}$, and $Z_{A, \mathrm{TDT}}$. Prior to the start of the test, the high-speed video camera was calibrated to obtain a transformation from pixel coordinates to physical space. The pixel location of the target at the parachute apex in the high-speed video images was extracted using image-processing tools developed at the Jet Propulsion Laboratory (JPL). Determining the position of the apex in the TDT coordinate system required use of the camera calibration, along with knowledge of the pixel location of the apex target and the distance from the high-speed video camera to the target. The latter was obtained from the inflated geometry of the parachute models. Figure 10 shows a trace of the position (in TDT coordinates) of the apex of a DGB parachute model at nominal test condition 11 over 15 seconds during the dynamic motions test.

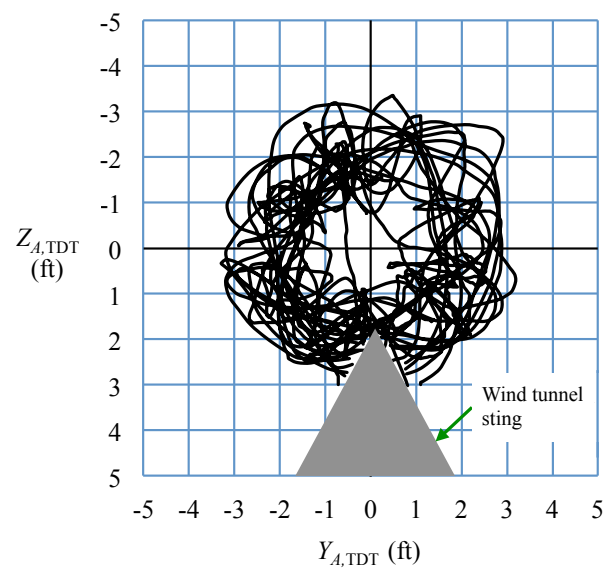

Figure 10. Example 15-Second Trace of $Y_{A, \mathrm{TDT}}$ versus $Z_{A, \mathrm{TDT}}$ for a DGB

Because the parachute apex is always downstream of the origin of the TDT coordinate system, $X_{A, \mathrm{TDT}}$ is always negative. Taking the position of the apex as the end of a vector with its origin at the TDT coordinate system (i.e., a 
vector along the axis of symmetry of the parachute from the triple bridle confluence point to the apex, assuming the parachute is a rigid body) allows for the definition of the geometric pull angle, $\Theta_{G}$, and the clock orientation of the geometric pull angle, $\Phi_{G}$. These angles are defined by:

$$
\begin{gathered}
L_{\mathrm{Tot}}=\sqrt{X_{A, \mathrm{TDT}}^{2}+Y_{A, \mathrm{TDT}}^{2}+Z_{A, \mathrm{TDT}}^{2}} \\
\Theta_{G}=\arccos \left(\frac{-X_{A, \mathrm{TDT}}}{L_{\mathrm{Tot}}}\right) \quad 0 \leq \Theta_{G} \leq \pi
\end{gathered}
$$

The clock orientation of the geometric pull angle is defined by:

$$
\Phi_{G}=\arctan \left(\frac{Y_{A, \mathrm{TDT}}}{Z_{A, T D T}}\right) \quad-\pi<\Phi_{G} \leq \pi
$$

Figure 11 graphically shows the definitions of $\Theta_{G}$ and $\Phi_{G}$. Notice that the arctan function used in Equation (16) retains the quadrant information (i.e., atan2 in most software). The geometrically-defined angles $\Theta_{G}$ and $\Phi_{G}$ are analogous to the force-defined angles $\Theta_{P}$ and $\Phi_{P}$. If the parachute force vector is exactly along the line from the triple bridle confluence point to the apex, then $\Theta_{G}=\Theta_{P}$ and $\Phi_{G}=\Phi_{P}$. The earlier remarks regarding $\Theta_{P}$ as a metric for parachute behavior also apply to $\Theta_{G}$.

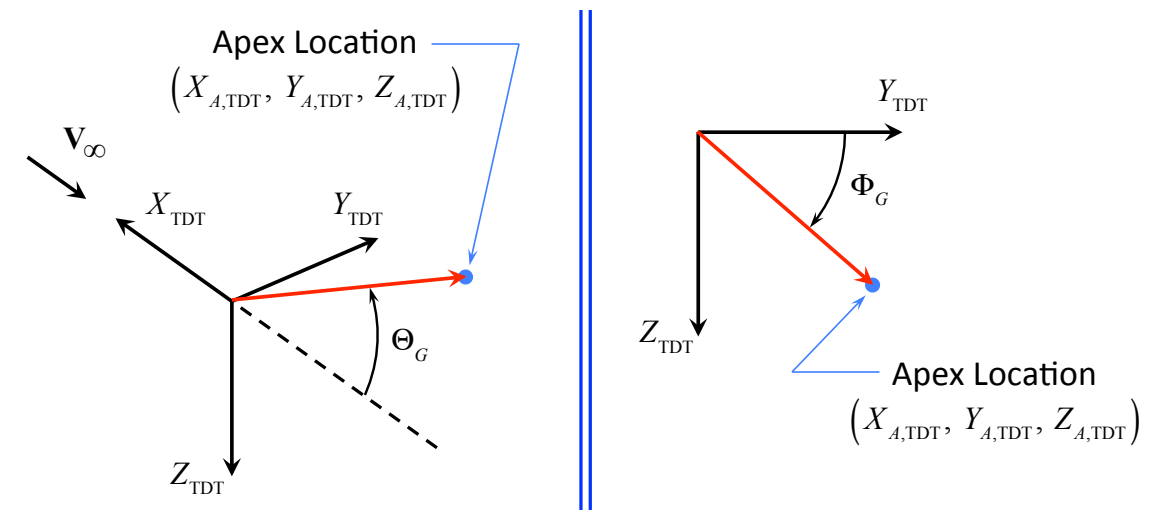

Figure 11. Definition of $\Theta_{G}$ and $\Phi_{G}$

An alternate manner for describing the attitude of the parachute is to specify the azimuth, $\psi$, and elevation, $\theta$, Euler angles (using the standard aerospace Euler angle definitions with rotation sequence $\psi \rightarrow \theta \rightarrow \phi$; the bank angle $\phi$ is assumed to be zero ${ }^{\#}$ ). These Euler angles $\psi$ and $\theta$ were calculated from:

$$
\begin{gathered}
\psi=\arctan \left(\frac{Y_{A, \mathrm{TDT}}}{X_{A, \mathrm{TDT}}}\right) \quad-\pi<\psi \leq \pi \\
\theta=\arctan \left(\frac{\sqrt{Y_{A, \mathrm{TDT}}^{2}+Z_{A, \mathrm{TDT}}^{2}}}{X_{A, \mathrm{TDT}}}\right) \quad-\frac{\pi}{2} \leq \theta \leq \frac{\pi}{2}
\end{gathered}
$$

Notice that the arctan function used in Equation (17) retains the quadrant information (i.e., atan2 in most software).

\# During testing, the bank angle, $\phi$, was observed to vary. Rotation rates up to approximately $\dot{\phi}=2 \pi \mathrm{rad} / \mathrm{s}\left(360^{\circ} / \mathrm{s}\right.$, $1 \mathrm{~Hz}$ ) were observed. 
Figure 12 graphically shows the definitions of $\psi, \theta$, and $\phi$ (using double-arrow right-hand-rule notation to specify the positive direction of $\phi$ ).

For the non-reefed parachutes (most of the data), $120 \mathrm{~Hz}$ proved to be a sufficiently high frame rate to capture the parachute motions.

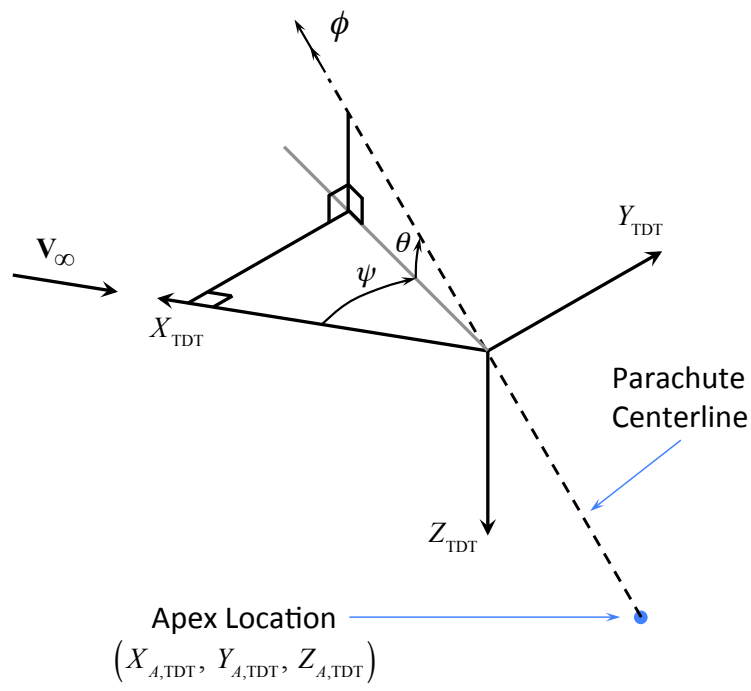

Figure 12. Definition of $\psi, \theta$, and $\phi$

\section{Results}

\section{A. Drag and Total Force Coefficients}

A summary of the drag coefficient results for all parachutes is shown in Fig. 13. As described previously, not all conditions were tested for each parachute, and some conditions were tested multiple times. Missing data points in Fig. 13 indicate that particular condition was not tested.

Figure 13 illustrates the first-order effect that fabric permeability has on the drag coefficient. For each parachute canopy type, the drag coefficient associated with a nominal test condition where data were available was consistently higher for the low permeability PIA-C-44378 Type I fabric, than the standard permeability, PIA-C-7020D Type I fabric. Changing the fabric material from standard to low permeability increased the drag coefficient of the SSRS parachute between 4.0 and $11.8 \%$, and increased the drag coefficient of the DGB between 7.4 and $19.6 \%$ (when multiple data points were available at a given nominal test condition this comparison is based on averaged values ).

Comparing results between parachute types using the same fabric material (at nominal test conditions where data were available for both parachute types), SSRS parachutes had higher drag coefficients than DGB parachutes for the sub-atmospheric nominal conditions (4 through 13). At atmospheric nominal test conditions (1 to 3), for parachutes using PIA-C-7020D Type I fabric, the SSRS parachutes had higher drag coefficients. However, at the same atmospheric nominal test conditions, for parachutes using PIA-C-44378 Type I fabric, SSRS and DGB parachutes had essentially the same drag coefficient. 


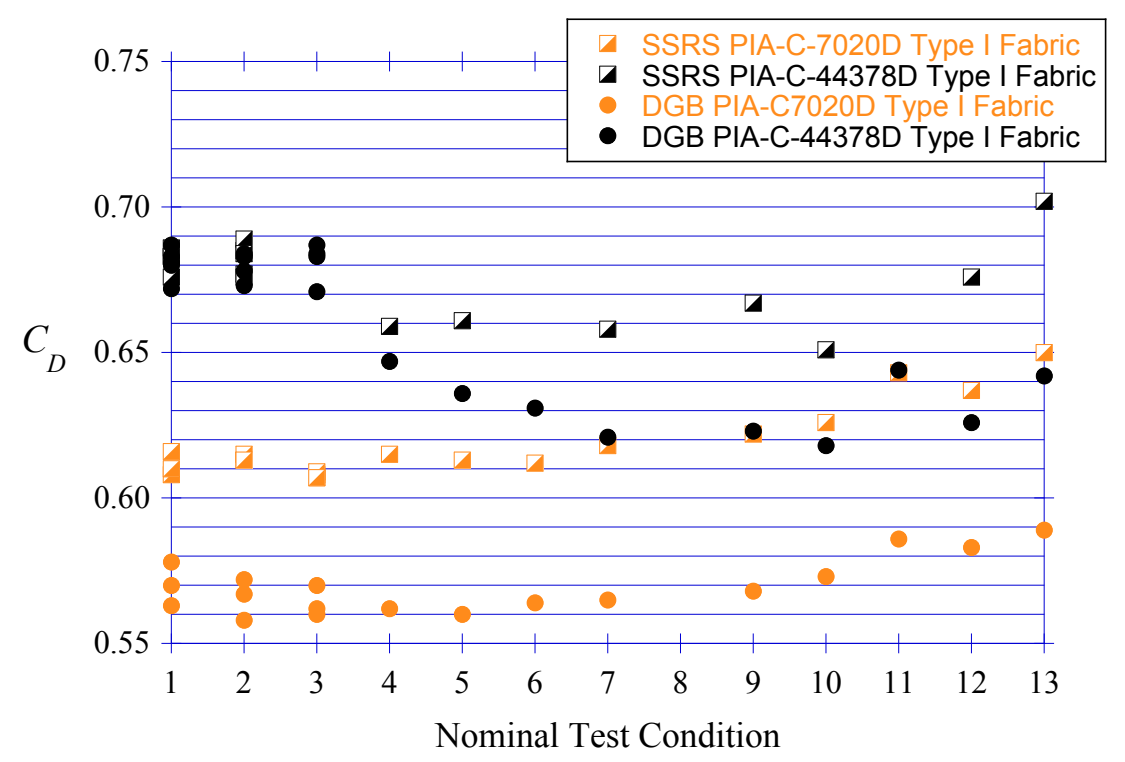

Figure 13. Summary of Drag Coefficient Results

Figure 14 shows the drag coefficients versus reefing ratio results for the reefed SSRS parachutes (the reefing ratio is the ratio of the reefing line length to the parachute nominal diameter, $D_{0}$ ). The reefed SSRS parachutes were only tested at atmospheric conditions. The relationship between drag coefficient and reefing ratio is approximately linear, and the trend is consistent with the unreefed drag coefficient values for the two parachute types. With the exception of the 0.5 reefing ratio, the drag coefficient of the reefed SSRS parachutes is higher for the low permeability fabric material than for the standard permeability fabric material.

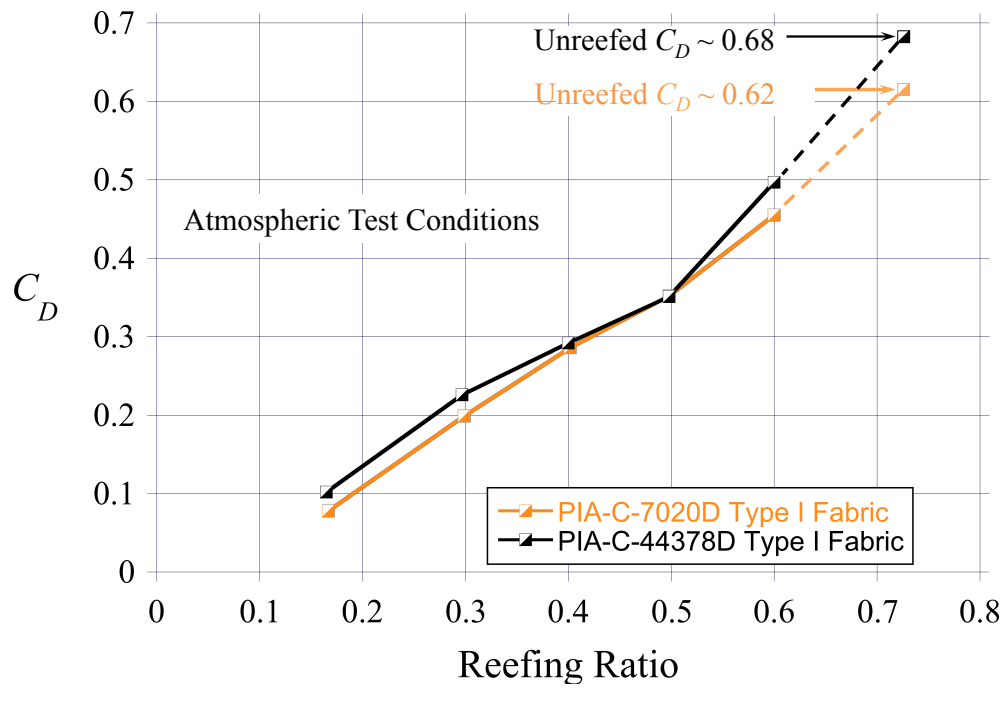

Figure 14. Summary of Reefed SSRS Drag Coefficients Results

\section{B. Static Coefficients}

An example of the static aerodynamic coefficient results for the SSRS parachute at nominal test condition 3 is shown in Fig. 15, for parachutes using both types of fabrics: PIA-C-7020D Type I (standard permeability, orange dashed lines), and PIA-C-44378D Type I (low permeability, solid black lines). The effects of fabric permeability on the static aerodynamic coefficients are evident: $\operatorname{larger} C_{T}$ at all $\alpha_{T}$ for the parachute using low permeability fabric, larger first stable total trim angle of attack for the parachute using low permeability fabric, larger restoring moment (i.e., increasingly negative values of $C_{m, \mathrm{SLCP}}$ ) for $\alpha_{T}$ greater than the first stable trim total angle of attack for the parachute using standard permeability fabric.

American Institute of Aeronautics and Astronautics 

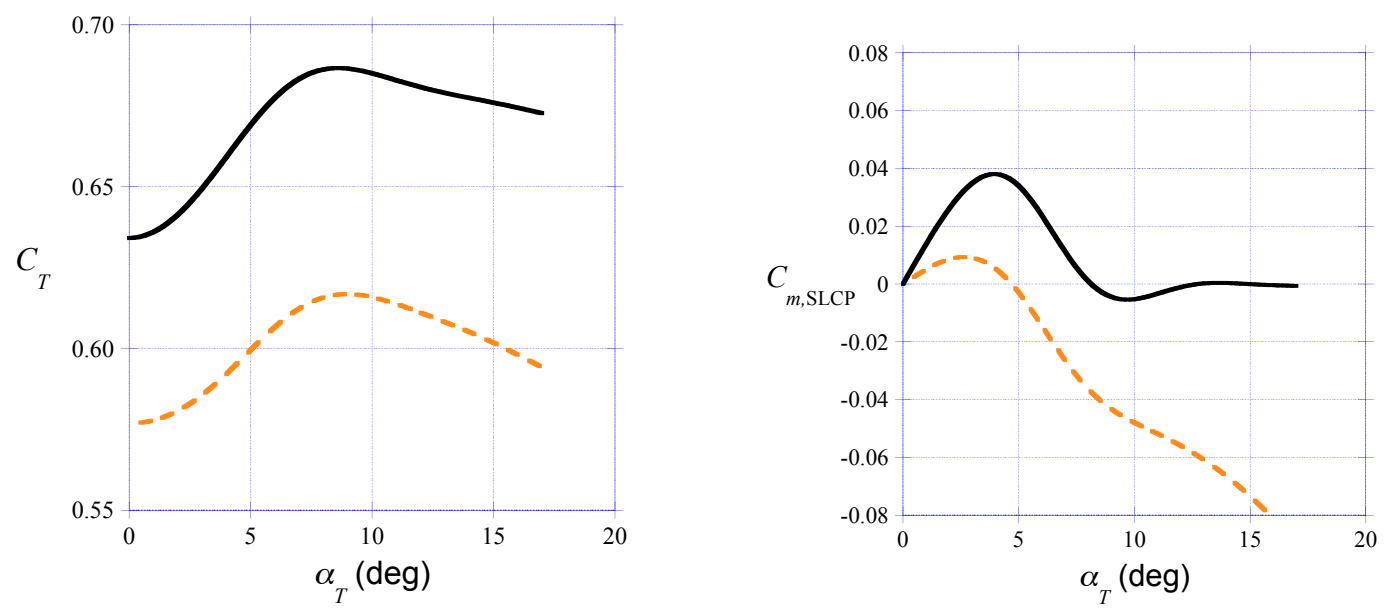

Figure 15. Example Static Aerodynamic Coefficient Results

Figure 16 presents a summary of the first stable trim total angle of attack, $\alpha_{T}$, for all non-reefed parachutes (as determined from $C_{m, \text { SLCP }}$ ). As stated previously, not all nominal test conditions were tested for each parachute. Additionally, for the SSRS parachute using PIA-C-44378D Type I fabric at nominal test conditions 4 and 5, no stable trim angle of attack were found within the range explored. Therefore, no data are available for these combinations. For nominal test condition 7, the total angle of attack for the SSRS parachute using PIA-C-44378D Type I fabric is $16.7^{\circ}$. This point is not shown in Fig. 16 because it distorts the vertical scale.

As with the drag coefficient, fabric permeability has a first order effect on the parachute aerodynamic characteristics, specifically near the first stable trim total angle of attack. While changing from a standard to low permeability fabric has the desirable effect of increasing the drag coefficient of the parachute, it has the undesirable effect of increasing the first stable trim total angle of attack. For the nominal test conditions where data were available, changing from standard permeability fabric to the low permeability fabric increased the first stable total trim angle of attack between 1.7 and 11.5 degrees for the SSRS parachutes, and increased the first stable total trim angle of attack between 2.1 and 3.6 degrees for the DGB parachutes.

Comparing parachutes of the same fabric material, the SSRS parachutes have first stable total trim angles of attack ranging from 0.7 to 1.6 degrees larger than those of the DGB parachutes for the standard permeability fabric material. For the low permeability fabric material, where data are available, the SSRS parachutes have larger first stable total trim angles of attack than the DGB parachutes for all nominal test conditions with the exception of conditions 11 through 13 . For nominal test condition 13, the SSRS has a slightly smaller (nearly 0.1 degrees) first stable total trim angle of attack than the DGB parachute. At nominal test conditions 11 and 12, the first stable trim angles of attack of the low permeability SSRS and DGB parachutes are very similar. 


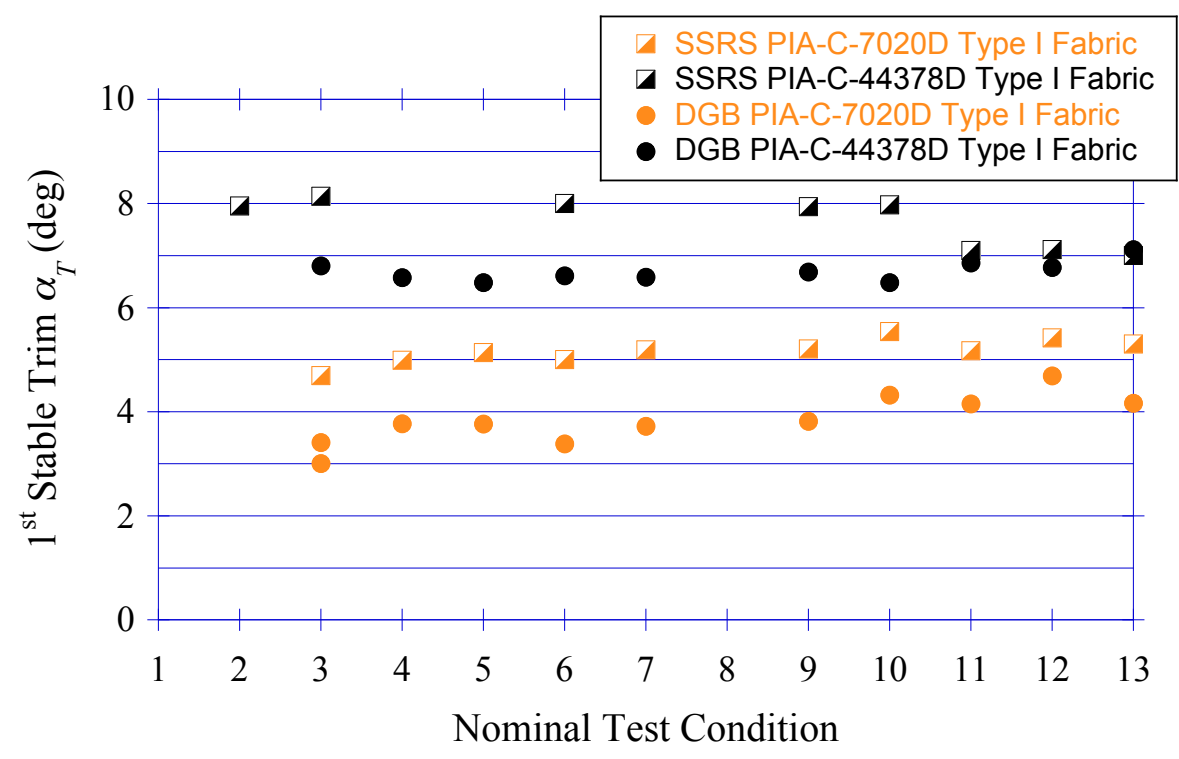

Figure 16. Summary of First Stable Trim Total Angle of Attack Results

\section{Dynamic Motions}

The dynamic motions results serve two purposes: to assess the parachute behavior and to create improved parachute aerodynamic models. This paper focuses on the first of these two purposes, therefore only a summary of the extensive dynamic motions data will be presented here, focusing on the force pull angles, $\Theta_{P}$. The force pull angle is characterized here by its $95^{\text {th }}$ percentile values, obtained by considering all the samples (typically 45,000 ) for a given test record. Figure 17 presents a summary of the $95^{\text {th }}$ percentile values of the force pull angle, for nonreefed parachutes. The $95^{\text {th }}$ percentile statistic was chosen for Figs. 17 and 18 since it represents a large value of $\Theta_{P}$ that is likely to occur.

As was observed in the drag coefficient and first stable total trim angle of attack, fabric permeability has a first order effect on the statistics of the force pull angle for the SSRS and DGB parachutes. For the nominal test conditions where data were available, changing from the standard to low permeability fabric increased the $95^{\text {th }}$ percentile value of the force pull angle for the SSRS parachute between 11.5 and 13.2 degrees, and between 6.0 and 7.7 degrees for the DGB parachute. For parachutes using the standard permeability fabric, tested at equivalent nominal conditions, the $95^{\text {th }}$ percentile value of the force pull angle for SSRS parachutes were smaller than those obtained with DGB parachutes. The opposite is true for parachutes using the low permeability fabric, tested at equivalent nominal conditions - the $95^{\text {th }}$ percentile value of the force pull angle for SSRS parachutes were larger than those obtained with the DGB parachutes. 


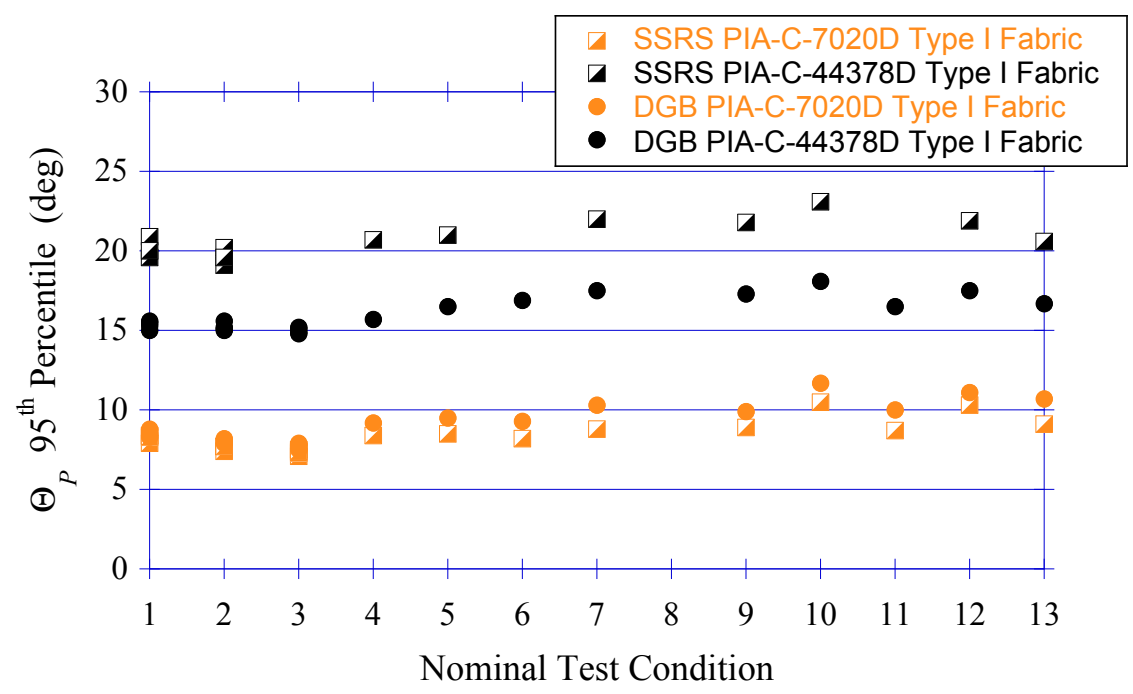

Figure 17. Summary of $95^{\text {th }}$ Percentile Force Pull Angle Results

The $95^{\text {th }}$ percentile results for the reefed SSRS parachutes are shown graphically in Fig. 18. Comparing the $95^{\text {th }}$ percentile values for the non-reefed SSRS parachutes in Fig. 17 with the values for the reefed SSRS parachutes in Fig. 18, for the nominal test conditions where data were available, shows smaller parachute pull angle values for the reefed parachutes when compared to the non-reefed parachutes.

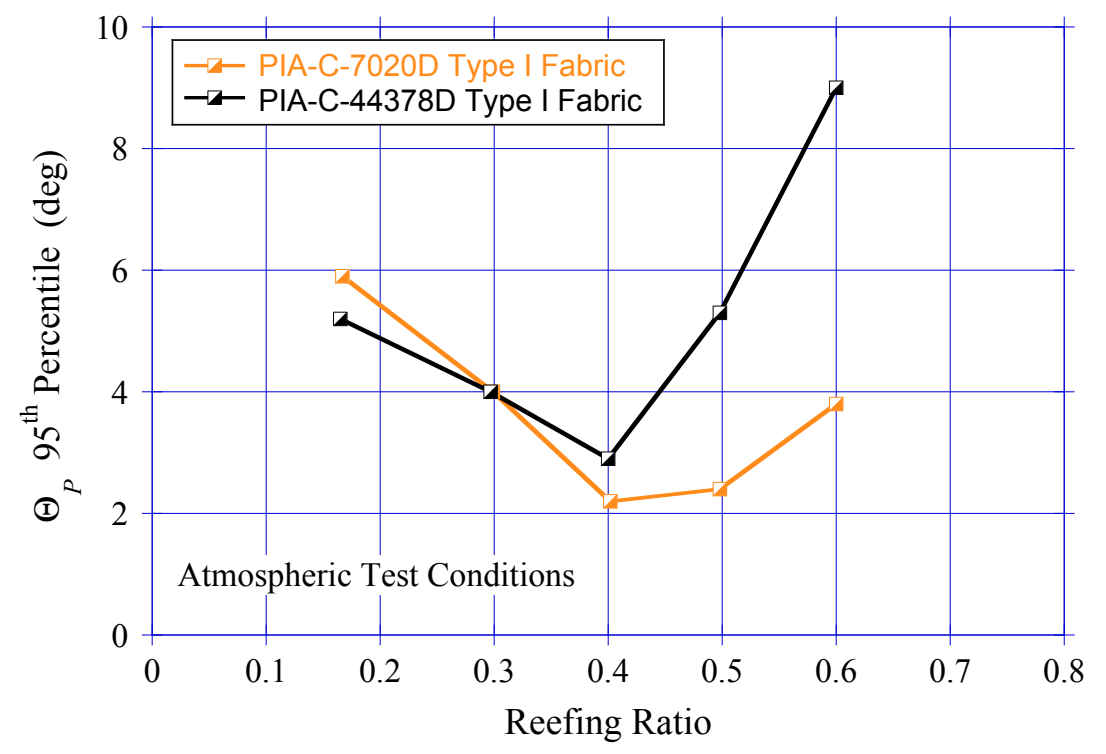

Figure 18. Summary of Reefed SSRS $95^{\text {th }}$ Percentile Force Pull Angle Results

\section{Conclusion}

The data collected and analyzed during this test has been compiled into a comprehensive database. These data will be used not only to update the current parachute aerodynamic models used in flight dynamics simulations for missions to Mars, but also to further understand and model the dynamic characteristics of the SSRS and DGB parachutes. A more extensive analysis of the permeability of the two materials used to fabricate the parachutes is currently underway, the results of which will allow for the interpolation of the test results to relevant Mars flight conditions. Upcoming missions such as Mars 2020 will directly benefit from new parachute aerodynamic models derived using the results of this test. 


\section{Acknowledgments}

The authors gratefully acknowledge the contributions of the following individuals and groups to the research presented herein. From the Langley Research Center: Jill Prince, Jennifer Pinkerton, Kenneth Toro, Raymond Mineck, Thomas Jones, and the entire Transonic Dynamics Tunnel Staff. From the Jet Propulsion Laboratory: Seth Aaron, John Luke Wolff, Ian Clark, and Christopher Tanner. From Old Dominion University, Prof. Drew Landman. The wind tunnel test was funded by the NASA Engineering and Safety Center (NESC) under assessment 14-00932 and the LDSD Project.

\section{References}

[1] Clark, I., Adler, M., Rivellini, T., "Development and Testing of a New Family of Supersonic Decelerators," 22nd AIAA Aerodynamic Decelerator Systems Conference, March 2013, AIAA 2013-1252.

[2] Cruz, J. R., Mineck, R. E., Keller, D. F., Bobskill, M. V., "Wind Tunnel Testing of Various Disk-Gap-Band Parachutes," AIAA Paper 2003-2129, 2003.

[3] Cruz, J. R., Way, D. W., Shidner, J. D., Davis, J. L., Adams, D. S., and Kipp, D. M., "Reconstruction of the Mars Science Laboratory Parachute Performance," Journal of Spacecraft and Rockets, Vol. 51, No. 4, pp. 1185-1196, July-August 2014.

[4] Parachute Industry Association, "Commercial Specification, Cloth, Parachute, Nylon-Rip Stop and Twill Weave," PIA-C-7020D, November 17, 2010.

[5] Parachute Industry Association, "Commercial Specification, Cloth, Parachute, Nylon, Low Permeability," PIA-C-44378D, May 3, 2007. 